This item was submitted to Loughborough's Research Repository by the author.

Items in Figshare are protected by copyright, with all rights reserved, unless otherwise indicated.

\title{
Dynamic measurements of the wind power impact on power system inertia and stability
}

PLEASE CITE THE PUBLISHED VERSION

https://doi.org/10.1109/ISGT-Asia.2018.8467973

\section{PUBLISHER}

(C) IEEE

\section{VERSION}

VoR (Version of Record)

\section{PUBLISHER STATEMENT}

This work is made available according to the conditions of the Creative Commons Attribution-NonCommercialNoDerivatives 4.0 International (CC BY-NC-ND 4.0) licence. Full details of this licence are available at: https://creativecommons.org/licenses/by-nc-nd/4.0/

\section{LICENCE}

CC BY-NC-ND 4.0

\section{REPOSITORY RECORD}

Chamorro, Harold R., Francisco M. Gonzalez-Longatt, and Vijay K. Sood. 2019. "Dynamic Measurements of the Wind Power Impact on Power System Inertia and Stability". figshare. https://hdl.handle.net/2134/33491. 


\section{Dynamic Measurements of the Wind Power Impact on Power System Inertia and Stability}

\author{
Harold. R. Chamorro \\ Royal Institute of Technology, \\ Stockholm, Sweden \\ hr.chamo@ieee.org
}

\author{
Francisco Gonzalez-Longatt \\ Loughborough University, \\ Loughborough, United Kingdom \\ fglongatt@fglongatt.org
}

\author{
Vijay K. Sood \\ University of Ontario, \\ Ontario, Canada \\ vijay.sood@uoit.ca
}

\begin{abstract}
The integration of wind power generation (WPG) have many different impacts on the current power transmission and distribution systems. Most of them are related to their effect on the dynamic behaviour and frequency deviation during system frequency disturbances affecting the system inertia response. Different approaches have been presented to show the dynamic behaviour diminution, and several metrics have been proposed to quantify the impact of the inertia reduction. This scientific paper looks at the background system inertia problem, presenting some of the most significant contributions in observation of power system dynamic under high penetrations of WPG and presents two dynamic measurements. First one measures the damping ratio of the power lines quantifying it in an online fashion. The second one measures the frequency of an electrical power signal. The dynamic measurements are tested in a hypothetical active power signal with the inclusion of wind energy showing the affectivity of the dynamic measurements presented and the impact of wind farms in power systems. Finally, future work and conclusions are given.
\end{abstract}

Keywords - Dynamic Measurements, Frequency Control, Power Systems, Small Signal Stability, System Inertia, Wind Power.

\section{INTRODUCTION}

During the last two decades an enormous transformation of the power generation, and in general, in the power system infrastructure has been developed. The renewable energy technologies have started to be integrated into the portfolio in order to limit the global warming and counteract the pollution around the world. Hence, a better understanding of the operational challenges of high inclusion of non-synchronous generation in the power system is needed [1].

Several private and governmental institutions have manifested their concern about the short-term grid code changes and the impact of non-synchronous generation on the power system dynamics and planning. For instance, North American Electric Reliability Corporation (NERC), have experienced abrupt frequency declines and less-inertia response due to the non-synchronous generation installed [2]. Similar phenomena have been reported by the European Wind Energy Association (EWEA) [3]. Transmission System Operators (TSO) globally concern about how much non-synchronous generation can be reliably integrated onto the bulk and which dynamic consequences and improvement are necessary to deploy [4].

Therefore, new tools for measurements and control are required to detect and counter-measures undesired events that can affect the system drastically. One of the areas where the non-synchronous generation has been studied the most is the oscillatory stability [5].

Low-inertia operated systems require fast mechanism and real-time monitoring of low-frequency /damped oscillations along the transmission system since they can provoke a blackout or a critically unstable system [6]. Such monitoring and measurements should incorporate recent methods and technologies that allow transferring remote information to the regional centre, the controllers involved (e.g. Power System Stabilizer, PSS), and/or Phasor Data Concentrators (PDC) for analysis a posteriori.

Situational awareness technologies may have the ability to track those oscillations and establish secure stability margins that classify the frequencies and, disregard the noise or frequencies associated with other phenomena [7].

With the inclusion of non-synchronous generation, such monitoring and margins may reach different levels activating protections unnecessarily or generate islanding generation of the distributed energy resources involved [8].

Several studies have shown that a high penetration of nonsynchronous generation changes the oscillation ranges that alters the tuning of the controllers, and consequently requiring supplementary controllers for damping those oscillations [9].

The proposed method presented in this paper aims to track and monitor the oscillations propagated in the transmission lines active power, which is where the oscillations waves conform the oscillation paths. The method quantifies the damping and frequency while the oscillation is propagating and in the range of inter-area oscillations. This method differs from the common mode estimation methods since it does the monitoring directly from the signal. The information obtained can be directly sent to the protection and control systems involved. Moreover, it also can be applied to the oscillation monitoring of power systems with non-synchronous generation inclusion. Additionally, an overview of other relevant dynamic measurements applied to low-inertia power systems is given.

The document is structured as follows: In Section II an overview of significant contributions in inertia problem is given. In Section III is given some basics of wind energy conversion including the synthetic inertia state of the art and some control developments involved. Section IV presents the method applied and the measurements obtained. Finally, the conclusions and future point of view of this research are given. 


\section{OVERVIEW OF INERTIAL RESPONSE}

System inertia has been defined as a measurement of the total amount of kinetic energy stored in all spinning turbines due to the rotating mass of the rotor [10], and this has an important impact on the called the inertial response of the system. In a conventional power system, in case of sudden disconnection of a synchronous generator, the frequency drops increasing the ROCOF, as it is shown in Fig. 1. The system frequency dynamic is reflected and propagated in the power system instantaneously. During the first period, the inertial response of the spinning machines naturally reacts releasing kinetic energy to the grid [11]-[13]. The appropriate answer of the primary and secondary controllers (AGC - Automatic Generation Control) can fulfil the frequency margins and assure a correct compensation of the frequency deviation in the system [14]-[16]. Otherwise, the deep penetration and integration of wind energy in the current power systems have a significant change diminution in the average power inertia. This is due to wind turbines do not have a natural response to face frequency dips as synchronous generators [17], [18].

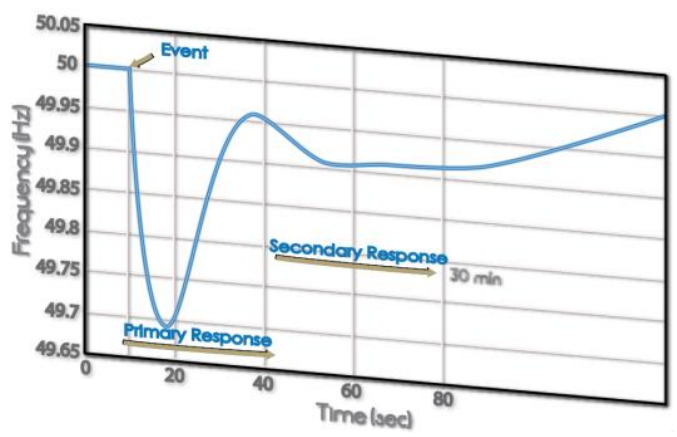

Fig. 1. Illustrative frequency response of a power system after sudden disconnection of a generator. Primary and secondary frequency response is indicated.

The reduced value of the inertia response by wind turbines generators (WTG) is a direct consequence of power-converter (PC) based technologies like Doubly Fed Induction Generator (DFIG) (Fig. 2) [19]. The DFIG and the full-rated PC technologies commonly a back-to-back ac/dc/ac PC as interface between the generator and the power net, it isolated the rotational inertia and the generator from the power system and inhibit it to provide any change in the power system frequency and consequently from the inertial response as well [20].

The traditional generators are equipped with automatic inner controllers. The idea of the controllers is to recover the system frequency, and the system frequency response can be divided in according to the actions. The first action affected is the Inertial Response (IR) which takes energy from the rotating masses, where the machine with the highest inertia contributes with the highest inertia power. This response is propagated through all the system via voltage angles and frequency provoking different decelerations in the power system machines. If the speed-power controllers actions are not done properly can cause rotor angle instability and the loss of synchronism of the machines involved. Fig. 3 shows a typical

frequency response of different synchronous generators (SGs) after a system frequency disturbance (SFD).

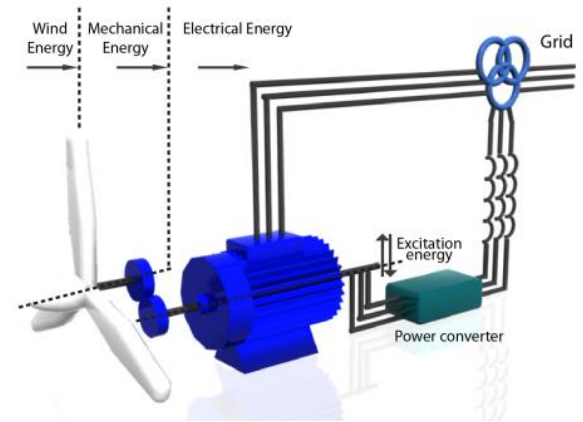

Fig. 2. Representative scheme of a WTG using DFIG. The rotor connected power converter (PC) is represented.

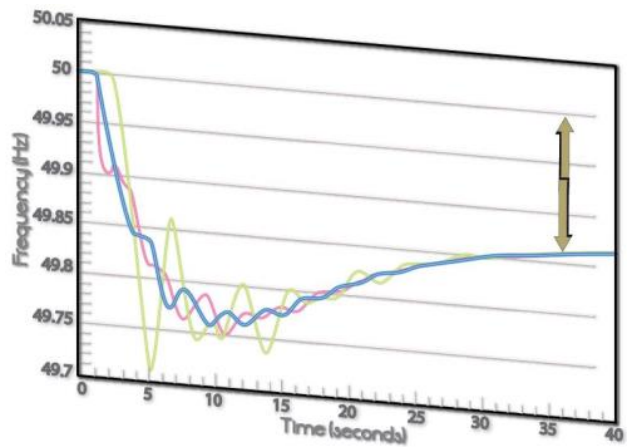

Fig. 3. Illustrative examples of system frequency response of three different SGs subject to an SFD.

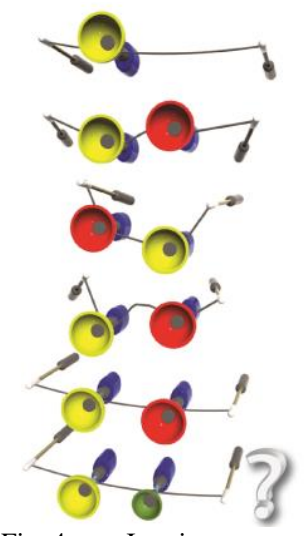

Fig. 4. Inertia Representation

Gyroscopic motion can be used to describe the spinning effect of WT rotors [21]. As an analogy to represent the kinetic inertia presented in power systems, it is possible to depict the inertia as the energy stored in a Chinese yo-yo spinning and its rotation. It continues rotating after the energy source is removed, and it is possible to add more than one and stabilize and synchronize them under an external control action with a string. When two rotating yoyos are involved a different speed, and coordination control is required to stabilize them, but what would happen with the control action when it is replaced one of them with a smaller one. The system inertia will change, and the external control action will be different. Fig. 5 shows an initial state of system stability, then the recovery under the string action. In a conventional power system, the rotating 
machines and the controllers involved are in charge to support the inertia system response automatically with coordination and synchronization. The same question presented above is what would happen if it is included an energy source with not enough of system inertia. Fig. 5 shows the power system inertia representation.

\section{WIND POWER IMPACT ON MEASUREMENTS}

Low-inertia operated systems, and potential improvements have been studied by several authors. Similarly, representative dynamic measurements have been identified by the gradual integration of non-synchronous generation as well as novel methods have been studied to counteract the inertia reduction and its dynamic impact [22].

Small signal stability studies with large non-synchronous inclusion have shown that a drastic change in the frequency/damping relation, displacing the action of the PSSs involved and changing the oscillation paths in the system. Root locus analysis can be interpreted as a tool which presents such changes after linearizing the system in a static window frame. Identifying changes in the modes including non-synchronous generation it is possible to identify potential tuning in the respective controllers involved in the modes damping and designing supplementary controllers to improve the system response [23].

The active power includes a kind of inertial effect. In the reactive power case, the wind farm emulates the behaviour of a Static Var Compensator (SVC) [24] .

An interesting performance index-based eigenvalue sensitivity is presented in [25] and applied to quantify the DFIG based WPG impact on the power systems inertia. This index is expressed as follows:

$$
\frac{\partial \lambda_{i}}{\partial H_{j}}=\frac{w_{i} \frac{\partial A}{\partial H_{j}} v_{i}^{T}}{v_{i}^{T} v_{i}}
$$

where $H_{j}$ is the inertia of $j^{\text {th }}$ conventional synchronous generator, $\lambda^{i}$ is the $i^{\text {th }}$ eigenvalue, $w_{i}$ and $v_{i}$ is the left and the right eigenvector corresponding to $i^{\text {th }}$ eigenvalue respectively. This index provides a good metric to estimate the impact due to increased DFIG penetration on system dynamic performance.

Power Systems Engineering Research Center (PSERC) in its report [26], establishes that is possible to identify the interarea modes and apply the concept of participation factors to excite them in the time domain. In addition to the sensitivity analysis, the same report evaluates the transient stability to see the effect of excitation in the low damped modes. An index which measures the severity is presented into, and expressed based on the angle margin as follows:

$$
T S I=\frac{360-\delta_{\max }}{360+\delta_{\max }} \times 100 \quad-100<\text { TSI }<100
$$

where $\delta_{\max }$ is the maximum angular separation of any two generators in the system at the same time in the post-fault response.
Reference [27], proposes different performance metric factors to measure the impact frequency performance of Wind Turbines. These factors are obtained after studying some cases in California. The following explains the factor and its impact on frequency response briefly. $K_{t}$ (Governor's Participation): These metrics quantify the governor's response according to the numbers of them involved.

Frequency Nadir: According to the report [27], this factor is used as a measurement of the inertia in the frequency response. The frequency deviation has a slight impact and nearly invisible. However, when is isolated the impact response on active governors, there is a substantial drop. It is concluded that the number of units and the speed response of governors. It can be obtained some derivative metrics such as frequency nadir time, nadir-based frequency response and settling frequency.

Headroom Deviation: This metric observes the dispatch of the active governors. The response shows that governor with higher initial power levels has a faster response, nevertheless there is no a high impact on frequency. An important observation can be done tracing the frequency nadir as a function of the governor participation. From this metric can be derived another metrics, the minimum and extreme minimum head-room [27].

ROCOF dynamic measurement has been proposed in the islanding detection of wind turbines in [48], where is used to detect circuit breaker levels and to quantify the inertia effect variation on. This measurement uses a frame which is updated according to the voltage waveform following the equation (3):

$$
\frac{d f}{d t}=\sum_{i=1}^{n} \frac{\Delta f_{i}}{\Delta t_{i}}
$$

where $\Delta f_{i}$ is the frequency change at the cycle, $i$ and $\Delta t_{i}$ is the duration of the $i^{\text {th }}$ cycle, and $n$ is the dynamic frame window width in cycles.

Wind farms (WFs) can contribute to diminishing the frequency deviation trying to imitate the behaviour of the rotational energy response of synchronous generators [28]. The objective of this emulation is to deliver some kinetic energy to the inertial response of the system taken into account the ROCOF under active power control [29], so that in this sense it is necessary to do a proper quantification of the frequency. Some interesting applications using syncrophasors units have been made concerning measuring power oscillations [30], and ROCOF monitoring to protect the system and avoid out of synchronism in the presence of high distribution generation penetration [31].

\section{Proposed Dynamic Measurements}

The importance of studying the impact of WPGs on power systems and, quantify the measurement of damping ratio effectively and frequency is the first step to develop a correct control action. In this section, the proposed dynamic measurements is presented [32]. Fig. 6 shows the relation of these measurements and the control system. 


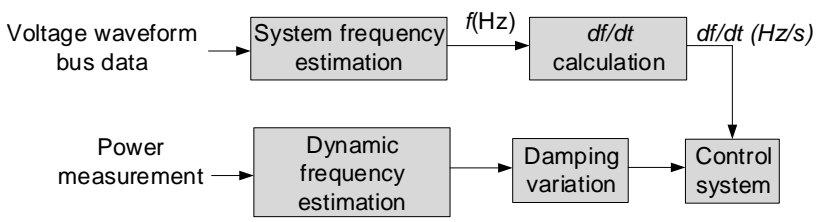

Fig. 6. A schematic block diagram of the proposed measurements and control system.

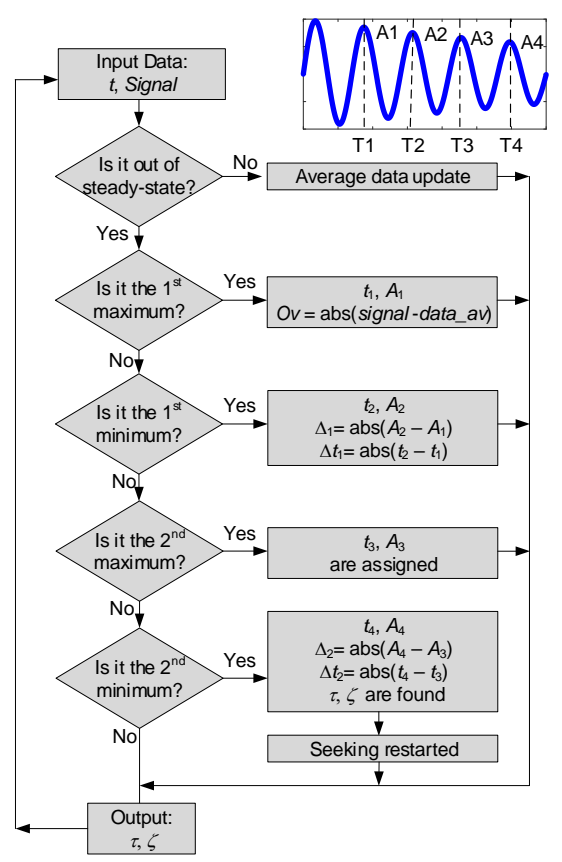

Fig. 7. Proposed algorithm of dynamic measurement: Damping

\section{A. Dynamic Damping Measurement}

An algorithm is developed to measure the damping factor of any signal, not only a power signal but supposing that the signal is filtered already, as it can be seen in Fig. 7. In order to test the algorithm, it is simulated a typical signal in MatlabSimulink ${ }^{\circledR}$ with the next characteristic equation, knowing the constant parameters $x=k \mathrm{e}^{n t} \sin (\omega t)$. Fig. 8 shows the signal introduced and the damping factor obtained.

\section{B. Dynamic Frequency Measurement}

Once is calculate the period of the signal as it is shown in the algorithm presented in Fig. 8, it can be calculated the frequency of the signal. An example measurement is presented in Fig. 9 where, as it is expected the frequency measurement is obtained according to the known signal parameters.

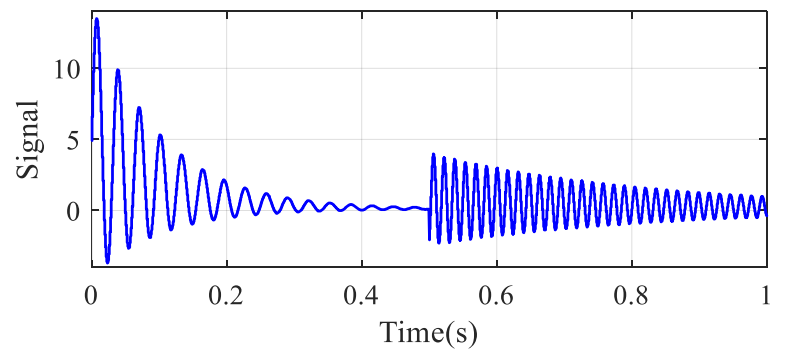

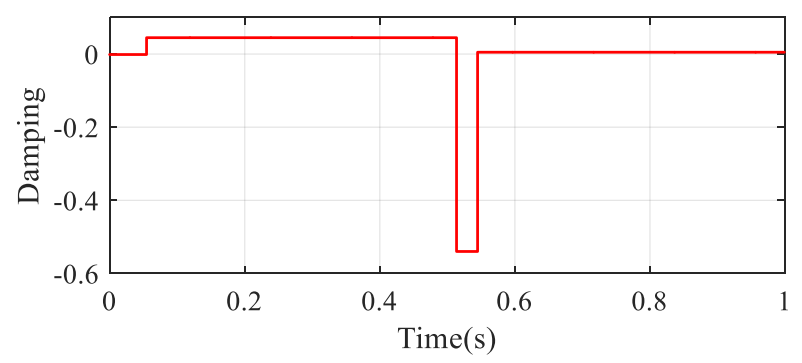

Fig. 8. Damping Measurement

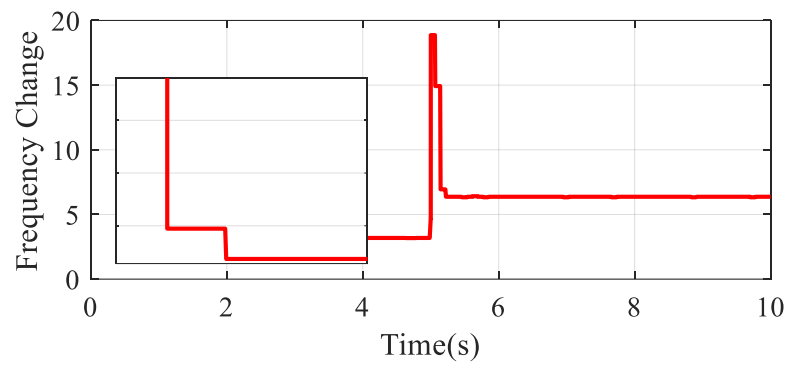

Fig. 9. Frequency Measurement

\section{CONCLUSIONS}

In this paper, a review of the current research on the impact quantification and measurements of wind power on power system stability is presented. Proposed dynamic measurements can be used in future control systems to evaluate the impact of the integration of wind power in traditional power systems. It is necessary to evaluate the impact of the increasing penetration of DFIG based WTG in the inertia system applying small signal stability in order to quantify its changes under disturbances.

\section{REFERENCES}

[1] A. Bonfiglio, F. Delfino, F. Gonzalez-Longatt, and R. Procopio, "Steadystate assessments of PMSGs in wind generating units," Int. J. Electr. Power Energy Syst., vol. 90, pp. 87-93, Sep. 2017.

[2] M. Reynolds, D. Stidham and Z. Alaywan, "The Golden Spike: Advanced Power Electronics Enables Renewable Development Across NERC Regions," in IEEE Power and Energy Magazine, vol. 10, no. 2, pp. 71-78, March-April 2012.

[3] J. De Decker, P. Kreutzkamp, A. Woyte and C. Dierckxsens, "The impact of large-scale offshore electricity transmission: The European project OffshoreGrid," 2012 9th International Conference on the European Energy Market, Florence, 2012, pp. 1-8.

[4] M. Peydayesh, J. Matevosyan and R. Baldick, "Study ERCOT fastresponding regulation service using frequency modeling tool," 2018 IEEE Texas Power and Energy Conference (TPEC), College Station, TX, USA, 2018, pp. 1-6.

[5] H. R. Chamorro, M. Ghandhari and R. Eriksson, "Influence of the increasing non-synchronous generation on Small Signal Stability," 2014 IEEE PES General Meeting | Conference \& Exposition, National Harbor, MD, 2014, pp. 1-5.

[6] Nahid-Al-Masood, N. Modi and R. Yan, "Low inertia power systems: Frequency response challenges and a possible solution," 2016 Australasian Universities Power Engineering Conference (AUPEC), Brisbane, QLD, 2016, pp. 1-6.

[7] P. Arunagirinathan and G. K. Venayagamoorthy, "Situational awareness 
in an electric utility's control center of its generators' damping capabilities," 2017 IEEE Power \& Energy Society Innovative Smart Grid Technologies Conference (ISGT), Washington, DC, 2017, pp. 1-5..

[8] A. Anujan, B. K. Johnson and E. J. William, "PROTECTION studies of geographically dispersed type 3 wind energy systems," 2017 IEEE Power \& Energy Society General Meeting, Chicago, IL, 2017, pp. 1-5.

[9] H. R. Chamorro, C. A. Ordonez, J. C. H. Peng, F. Gonzalez-Longatt, V. K. Sood and A. M. Sharaf, "Impact of non-synchronous generation on transmission oscillations paths," 2018 IEEE Texas Power and Energy Conference (TPEC), College Station, TX, USA, 2018, pp. 1-6.

[10]H. R. Chamorro, N. R. Malik, F. Gonzalez-Longatt, and V. K. Sood, "Evaluation of the synthetic inertia control using active damping method," in 2017 6th International Conference on Clean Electrical Power (ICCEP), 2017, pp. 269-274.

[11]Z. WU et al., "State-of-the-art review on frequency response of wind power plants in power systems," J. Mod. Power Syst. Clean Energy, vol. 6, no. 1, pp. 1-16, Jan. 2018.

[12]J. Björnstedt, "Integration of Non-synchronous Generation -Frequency Dynamics," Lund University, 2012

[13]F. M. Gonzalez-Longatt, "Impact of emulated inertia from wind power on under-frequency protection schemes of future power systems," J. Mod. Power Syst. Clean Energy, vol. 4, no. 2, 2016.

[14] "Definition and Classification of Power System Stability IEEE/CIGRE Joint Task Force on Stability Terms and Definitions," IEEE Trans. Power Syst., vol. 19, no. 3, pp. 1387-1401, Aug. 2004.

[15]I. Egido, F. Fernández-Bernal, and L. Rouco, "Evaluation of Automatic Generation Control (AGC) regulators by performance indices using data from real operation," IET Gener. Transm. Distrib., vol. 1, no. 2, p. 294, 2007.

[16]G. Andersson, "Dynamics and Control of Electric Power Systems." Zurich, p. 125, 2012

[17]B. Khaki, M. H. Asgari, R. Sirjani, and A. Mozdawar, "Contribution of DFIG wind turbines to system frequency control," in 2009 International Conference on Sustainable Power Generation and Supply, 2009, pp. 1-8..

[18]H. R. Chamorro, C. A. Ordonez and J. F. Jimenez, "Coordinated control based Petri Nets for Microgrids including wind farms," 2012 IEEE Power Electronics and Machines in Wind Applications, Denver, CO, 2012, pp. 1-6.

[19] M. Bollen and F. Hassan, Integration of Distributed Generation in the Power System. Hoboken, NJ, USA: John Wiley \& Sons, Inc., 2011.

[20]G. Lalor, A. Mullane, and M. O’Malley, "Frequency Control and Wind Turbine Technologies," IEEE Trans. Power Syst., vol. 20, no. 4, pp. 1905-1913, Nov. 2005.

[21] J. F. Manwell, J. G. McGowan, and A. L. Rogers, Wind Energy Explained. Chichester, UK: John Wiley \& Sons, Ltd, 2009.

[22]H. R. Chamorro, C. A. Ordonez, J. C. Peng and M. Ghandhari, "Nonsynchronous generation impact on power systems coherency," in IET Generation, Transmission \& Distribution, vol. 10, no. 10, pp. 2443-2453, 772016.

[23] Y. Pan et al., "Towards the Robust Small-Signal Stability Region of Power Systems Under Perturbations Such as Uncertain and Volatile Wind Generation," in IEEE Transactions on Power Systems, vol. 33, no. 2, pp. 1790-1799, March 2018.

[24]E. Spahic, C. P. Susai Sakkanna Reddy, M. Pieschel and R. Alvarez, "Multilevel STATCOM with power intensive energy storage for dynamic grid stability - frequency and voltage support," 2015 IEEE Electrical Power and Energy Conference (EPEC), London, ON, 2015, pp. 73-80.

[25] T. Smed, "Feasible eigenvalue sensitivity for large power systems," IEEE Trans. Power Syst., vol. 8, no. 2, pp. 555-563, May 1993.

[26] V. Vittal and P. Leader, "Impact of Increased DFIG Wind Penetration on Power Systems and Markets Final Project Report."

[27] N. W. Miller, M. Shao, and S. Venkataraman, "California ISO (CAISO)," 2011.

[28]F. Gonzalez-Longatt, A. Bonfiglio, R. Procopio and D. Bogdanov, "Practical limit of synthetic inertia in full converter wind turbine generators: Simulation approach," 2016 19th International Symposium on Electrical Apparatus and Technologies (SIELA), Bourgas, 2016, pp. 1-5.
[29]H. R. Chamorro, A. C. Sanchez, A. Øverjordet, F. Jimenez, F. GonzalezLongatt and V. K. Sood, "Distributed synthetic inertia control in power systems," 2017 International Conference on ENERGY and ENVIRONMENT (CIEM), Bucharest, 2017, pp. 74-78.

[30]W. Dickerson, "Effect of PMU analog input section performance on frequency and ROCOF estimation error," 2015 IEEE International Workshop on Applied Measurements for Power Systems (AMPS), Aachen, 2015, pp. 31-36.

[31] M. R. A. Paternina, D. Guillen, R. K. Tripathy, A. Zamora, J. A. Huerta and J. C. Rosas-Caro, "Phasor, frequency and ROCOF measurements in microgrids: A practical approach," 2017 IEEE International Autumn Meeting on Power, Electronics and Computing (ROPEC), Ixtapa, 2017, pp. 1-5.

[32]H. R. Chamorro and M. A. Rios, "Hierarchical PSS control for smart transmission grids - A multiagents system approach," 2013 IEEE Grenoble Conference, Grenoble, 2013, pp. 1-5. 